\title{
P Wave Body Surface Isointegral Maps in Children and in Young Adults
}

\author{
K. KOZLÍKOVÁ
}

Institute of Medical Physics, Biophysics, Informatics and Telemedicine, Faculty of Medicine, Comenius University, Bratislava, Slovak Republic

Received May 23, 2007

Accepted May 29, 2007

On-line available May 31, 2007

\begin{abstract}
Summary
Only limited data are available on body surface potential distribution during atrial activation. The aim of this study was to establish the distributions and to analyze chosen quantitative parameters of atrial isointegral maps recorded using a limited 24-lead system in a young healthy population. A total of 166 subjects underwent a procedure of body surface potential mapping. Isointegral maps during the $\mathrm{P}$ wave were constructed and qualitatively and quantitatively evaluated. Three types of atrial activation in individual maps were found according to the different shape of the zero isointegral line and to mutual positions of extrema. The most frequently occurring type resembled the group mean maps and was in good agreement with published data obtained from full lead systems. The highest extrema were found in the young men group, while, surprisingly, the lowest values in the young women group. All minima and the majority of maxima were recorded outside the ranges of standard chest leads. The usefulness of the limited lead system to record isointegral $\mathrm{P}$ wave maps was shown and new data were presented that can be useful in noninvasive evaluation of atrial pathologies.
\end{abstract}

\section{Key words}

Eletrocardiography $\bullet$ Body surface mapping $\bullet$ Heart atria

\section{Introduction}

Electrocardiographic body surface mapping is a noninvasive method that can show the spatial distribution of body surface potentials using numerous leads on a patient's front and back chest, permitting more complete visualization of cardiac electrical activity and, in this way, providing three-dimensional details on the electrocardiogram similar to those obtained with an invasive method. The rationale behind body surface mapping is an extension of additional lead ECG. The output from body surface mapping can be displayed in the form of a set of single leads or, more usually, in the form of a (flat) map.

The $\mathrm{P}$ wave in the surface ECG represents the atrial electrical activation and may be altered in certain pathological conditions sometimes relatively unexpected (Sleiman et al. 2000, Szlejf et al. 2002). As the research on body surface potential mapping concerned predominantly the ventricular excitation process, there is still only limited data available documenting body surface potential distribution during atrial electric events. This is mainly devoted to isopotential maps (Taccardi 1966, Mirvis 1980, Kawano et al. 1983, Ishihara et al. 1987, 
Popperová et al. 1988, Kalka et al. 1996). Lesser papers have been published that deal with body surface isointegral $\mathrm{P}$ wave maps under normal conditions, in chronic pulmonary emphysema, during pacing or in atrial fibrillation (Mirvis 1980, Ikeda et al. 1985, SippensGroenewegen et al. 1998, 2000, 2004). All mentioned papers describe $\mathrm{P}$ wave maps recorded by full lead systems using 62, 80, 87, and 150 leads. The existence of limited data concerning body surface mapping of atrial activation may be also due to the fact that $P$ waves have relatively small amplitudes and can be easily distorted by the noise. This can be at least partially avoided by using isointegral maps as they can stress small changes lasting a longer time.

The aim of this study was to establish the distributions and selected quantitative parameters of the atrial isointegral maps recorded using a limited 24-lead system in the young healthy population to support a prospective usefulness of the noninvasive registrations of surface maps in atrial arrhythmias and other pathologies.

\section{Methods}

A total of 88 normal females and 78 normal males with no history of cardiovascular disease and normal electrocardiographic and echocardiographic findings were studied (Kozlíková and Martinka 2004). They were divided into 6 groups according to their age and sex: group F1 - 17 girls (aged $9.8 \pm 0.3$ years $(y)$ ), group F2 - 25 girls $(13.5 \pm 0.4 \mathrm{y})$, group F3 - 46 women (18.5 $\pm 0.4 \mathrm{y}$ ), group M1 - 15 boys (aged $9.7 \pm 0.3 \mathrm{y}$ ), group M2 - 25 boys $(13.6 \pm 0.4 \mathrm{y})$, group M3 - 46 men $(18.6 \pm 0.4 \mathrm{y})$. All had normal blood pressure at the date of measurement (systolic: $118 \pm 14 \mathrm{mmHg}$, diastolic: $70 \pm 10 \mathrm{mmHg}$ ).

Body-surface mapping was done with the ProCardio mapping system (Rosík et al. 1997) using the 24-lead system after Barr depicted from the full grid of 10 rows $\times 15$ columns (Barr et al. 1971). Data were recorded in supine position during normal breathing (expiration). The onset and the offset of each $\mathrm{P}$ wave were established using the root mean square signal from 24 unipolar chest leads with Wilson's central terminal as reference and using the TP segment as a zero baseline (Kozlíková 1990, Kozlíková and Martinka 2004). A time integral in each measured lead represents the area between the zero baseline and the electrocardiographic curve during the chosen time interval. The integrals are displayed in the form of isointegral maps where the isointegral lines connect equal values. Single-beat isointegral maps were constructed for each subject and mean group maps were calculated.

Values of single-beat $\mathrm{P}$ wave isointegral maps extrema (maximum, minimum, peak-topeak $=$ maximum - minimum) and their positions were analyzed (Kozlíková 1990). All group data are presented either as mean \pm standard deviation or median and $95 \%$ confidence interval. Statistical evaluation was done using unpaired two-tailed Student's t-test and analysis of variance for means of normally distributed data; otherwise, medians were compared using the MannWhitney test or the Kruskal-Wallis test (Statgraphics ${ }^{\circledR}$ PLUS, 1997). A value of $p<0.05$ was considered statistically significant. Frequencies of map types were statistically evaluated using $\chi$-square test (contingency tables).

Type A:

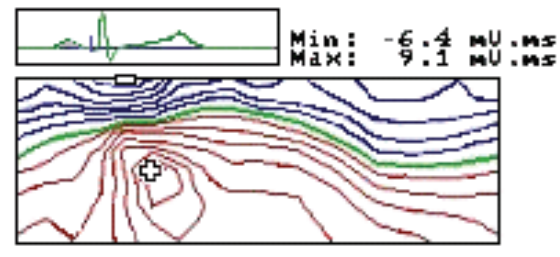

Type B:

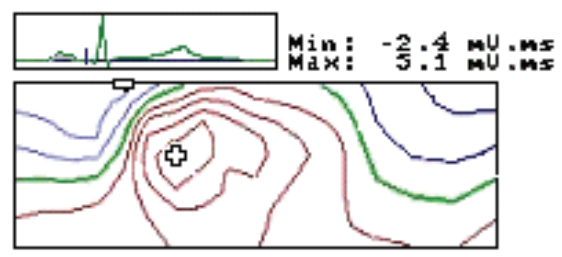

Type C:

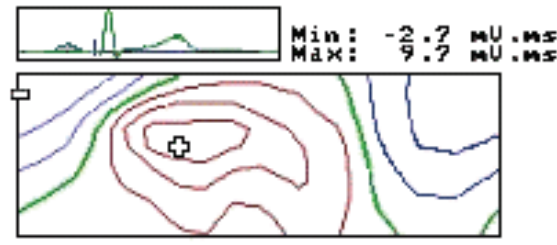

Fig. 1. Three main types of time integral distributions occurring in individual $\mathrm{P}$ wave isointegral maps of all analyzed groups. Each map is represented as an unrolled cylinder cut along the right mid-axillary line. The left and the right halves correspond to the front and the back of the chest, respectively. The increment between isointegral lines is linear and equals $1 \mathrm{mV}$.ms. The zero line is bolder. Plus and minus signs depict the location of maximum and minimum, respectively. Their values are given over each map together with the reference lead (II). The type $A$ was found in group M3, types $B$ and $C$ in group F3. All maps display smooth bipolar distributions. 
Group Fl:

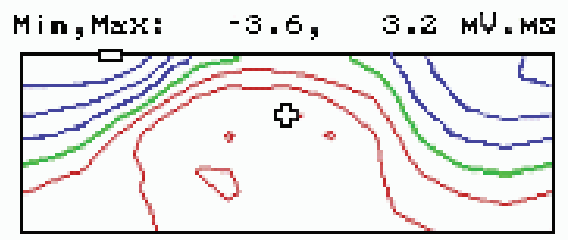

Group F2:

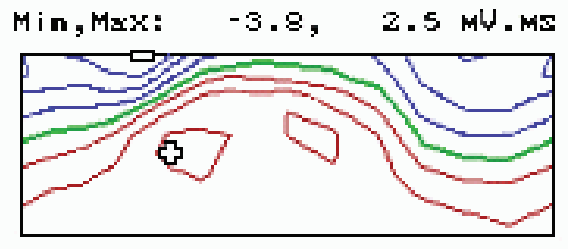

Group F3:

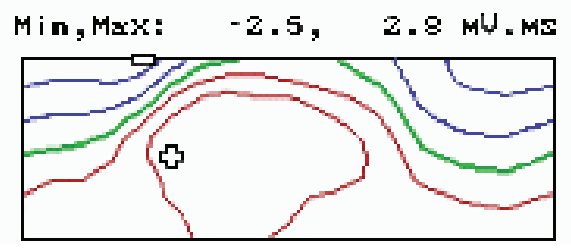

Fig. 2. Mean $P$ wave isointegral maps of all analyzed groups.

\section{Results}

Individual single beat maps revealed prevalent smooth dipolar distribution of positive and negative time integrals. The patterns could be divided into 3 main types: A, B, and C (Fig. 1, Table 1). Their frequencies differed significantly in the studied groups $(\chi$-square applied to all 6 groups: $p<0.05$ ).

Type A occurred in about $38 \%$ of maps, mainly in males. It was characterised by almost horizontal zero isointegral line separating the negativities covering continuously the upper chest and the positivities covering continuously the lower chest. The line connecting the maximum and the minimum was approximately vertical or oblique.

Type B occurred in about $45 \%$ of maps, mainly in females. It was characterised by oblique zero isointegral line separating the negativities covering the upper right chest and the positivities covering the lower right chest but also reaching the left shoulder. The line connecting the maximum and the minimum was oblique.

Type $\mathrm{C}$ occurred in about $17 \%$ of maps. It was characterized by almost vertical zero isointegral line separating the negativities covering the right chest and always reaching the bottom margin of the map and the positivities covering the left chest. The line connecting
Group M1:

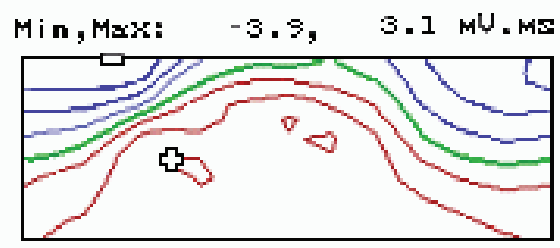

Group M2:

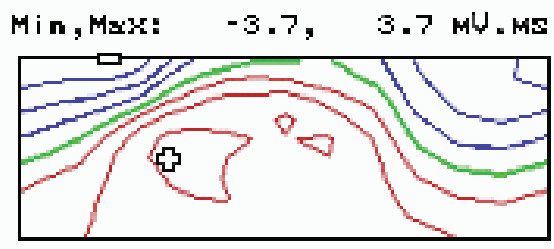

Group M3:

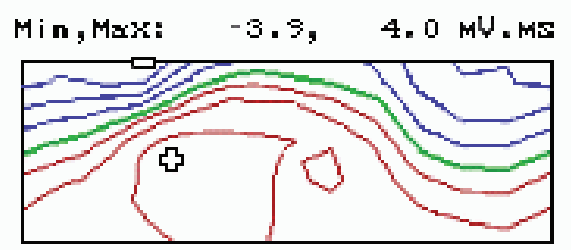

the maximum and the minimum was approximately horizontal or oblique.

Group mean maps revealed smooth distributions of negative time integrals (Fig. 2). They covered the upper parts of the chest, mainly its right side. Minimum in mean maps was always located parasternally right at the clavicular level.

Zero isointegral lines separating the positivity and the negativity roughly resembled a sinus curve.

Positive time integrals covered the lower parts of the chest and they reached the left shoulder resembling the type B in individual maps. They revealed two maxima in five of the six studied groups. The primary maximum of groups F2, M1, M2, and M3 was located to the left of the lower part of sternum, while the secondary maximum was located in the area of the left axilla and was almost at the same value $(80 \%$ to $100 \%$ of the primary maximum). In the youngest girls (group F1) the primary maximum was located in the area of the left axilla and the secondary one to the left of the lower part of sternum. There was only one maximum in the left of the lower part of sternum in the young women group (F3).

The existence of two maxima in mean maps can be explained by the position of maxima in the single-beat maps (Fig. 3). They covered mainly the left anterior chest with two dominant positions corresponding to the 
Table 1. Absolute and relative frequencies of the 3 types (A, B, $C)$ of time-integral distributions in individual single-beat maps.

\begin{tabular}{|c|c|c|c|c|}
\hline \multirow{2}{*}{ Group } & \multicolumn{4}{|c|}{ Map type } \\
\hline & & $\mathbf{A}$ & B & C \\
\hline$F 1$ & 3 & $(1.81 \%)$ & $12(7.23 \%)$ & $2(1.21 \%)$ \\
\hline$F 2$ & 12 & $(7.23 \%)$ & $9 \quad(5.42 \%)$ & $4(2.41 \%)$ \\
\hline$F 3$ & 13 & $(7.83 \%)$ & $22(13.25 \%)$ & $11(6.63 \%)$ \\
\hline M1 & 6 & $(3.61 \%)$ & $7 \quad(4.22 \%)$ & $2(1.21 \%)$ \\
\hline M2 & 9 & $(5.42 \%)$ & $10 \quad(6.02 \%)$ & $4(2.41 \%)$ \\
\hline M3 & 20 & $(12.05 \%)$ & $14(8.43 \%)$ & $6(3.61 \%)$ \\
\hline Sum & 63 & $(37.95 \%)$ & $74(44.57 \%)$ & $29(17.48 \%)$ \\
\hline
\end{tabular}

positions of maxima in mean maps. Only 9 out of 166 maxima were located in other positions ( 3 of 9 on the right lower chest and 6 of 9 on the back along the spine). The only statistically significant difference concerning the position of maxima was found between the youngest and the oldest male groups M1 and M3. The youngest boys had their maxima shifted more to the left approximately to the left medioclavicular line, while the group M3 maxima were positioned mainly to the left of the sternum $(p<0.05)$.

Minima in single beat maps were located mainly parasternally right at the clavicular level $(56 \%$ of all cases) or around the right shoulder. Only in two cases their position overlapped with that of the maxima (Fig. 3). The only significant difference concerning the position of minima was found between the groups M2 and M3. In the young men group, the minimum was closer to sternum $(p<0.05)$.

Although the positions of individual maxima partially overlapped with positions of the standard chest leads, the majority of maxima as well as all minima were recorded outside their areas.

The highest extrema (minima treated in their absolute values) were found in the young men (group M3), while the lowest in the young women (group F3, the "flattest" maps, Fig. 4). Medians with corresponding $95 \%$ confidence intervals for maxima were $5.0 \mathrm{mV} . \mathrm{ms}$ (4.7 mV.ms, $5.9 \mathrm{mV} . \mathrm{ms})$ versus $3.7 \mathrm{mV} . \mathrm{ms}(3.0 \mathrm{mV} . \mathrm{ms}$, $4.1 \mathrm{mV} . \mathrm{ms}), \quad p<0.001, \quad$ for minima $-4.5 \mathrm{mV} . \mathrm{ms}$ ( $-4.9 \mathrm{mV} . \mathrm{ms}, \quad-3.7 \mathrm{mV} . \mathrm{ms}) \quad$ versus $\quad-2.7 \mathrm{mV} . \mathrm{ms}$ ( $-3.1 \mathrm{mV} . \mathrm{ms},-2.3 \mathrm{mV} . \mathrm{ms}), p<0.001$; for peak-to-peak values $9.6 \mathrm{mV} . \mathrm{ms} \quad(8.5 \mathrm{mV} . \mathrm{ms}, \quad 11.6 \mathrm{mV} . \mathrm{ms})$ versus $6.4 \mathrm{mV} . \mathrm{ms}$ (5.6 mV.ms, $7.2 \mathrm{mV} . \mathrm{ms}), p<0.001$. There were no significant differences concerning any extreme values between different sexes in the two younger groups. Maxima increased with increasing age in males with the only significant difference between the group M3 and the group M1 (3.7 mV.ms $\quad(3.2 \mathrm{mV} . \mathrm{ms}, \quad 4.3 \mathrm{mV} . \mathrm{ms})$, $p<0.01)$. There were no statistically significant differences between female groups.

Although the minima became deeper with increasing age of males, no statistically significant differences were found opposite to females. The minima in the oldest group F3 differed significantly from the minima of both younger groups F2 $(-4.1 \mathrm{mV} . \mathrm{ms}$ $(-4.7 \mathrm{mV} . \mathrm{ms}, \quad-2.7 \mathrm{mV} . \mathrm{ms}), \quad p<0.01) \quad$ and $\quad \mathrm{F} 1$ ( -4.0 mV.ms $(-4.5 \mathrm{mV} . \mathrm{ms},-3.0 \mathrm{mV} . \mathrm{ms}), p<0.01)$.

Peak-to-peak values behaved similarly to the maxima but no statistically significant differences were found between different age groups.

\section{Discussion}

Three types of body-surface time-integral distributions in isointegral $\mathrm{P}$ waves were found. Unfortunately, there are only few papers dealing with body surface isointegral maps of $\mathrm{P}$ wave in healthy population so that it is almost impossible to obtain reliable comparisons. Nevertheless, our data were in good agreement with those published earlier although different race and different age groups have to be taken into account.

The individual isointegral $P$ wave map published by Mirvis (1980) resembled the type B in this paper although a different lead system (150 leads) and different display was used (the cylinder was cut along the spine).

Group mean maps published by Ikeda et al. (1985) were recorded in 20 males aged 35 to 51 years using 87 leads. The body surface distribution of time integrals in the published mean map was similar to that of the M3 group except for the number and the position of maximum. The single maximum of published maps was located in the position of the secondary maximum of group M3. There was no statistical difference concerning the group mean values of maxima and minima (published: $4.52 \pm 1.18 \mathrm{mV} . \mathrm{ms}$ and $-4.31 \pm 1.08 \mathrm{mV} . \mathrm{ms}$ versus group M3: $5.35 \pm 1.62 \mathrm{mV} . \mathrm{ms}$ and $-4.52 \pm 1.64 \mathrm{mV} . \mathrm{ms}$, respectively).

The majority of maxima and all minima were recorded outside the range of standard chest leads and even outside the exact positions of leads in the used limited lead system. This explains why body surface mapping can give additional information also in the relatively low-amplitude potentials, such as with the $\mathrm{P}$ waves. 


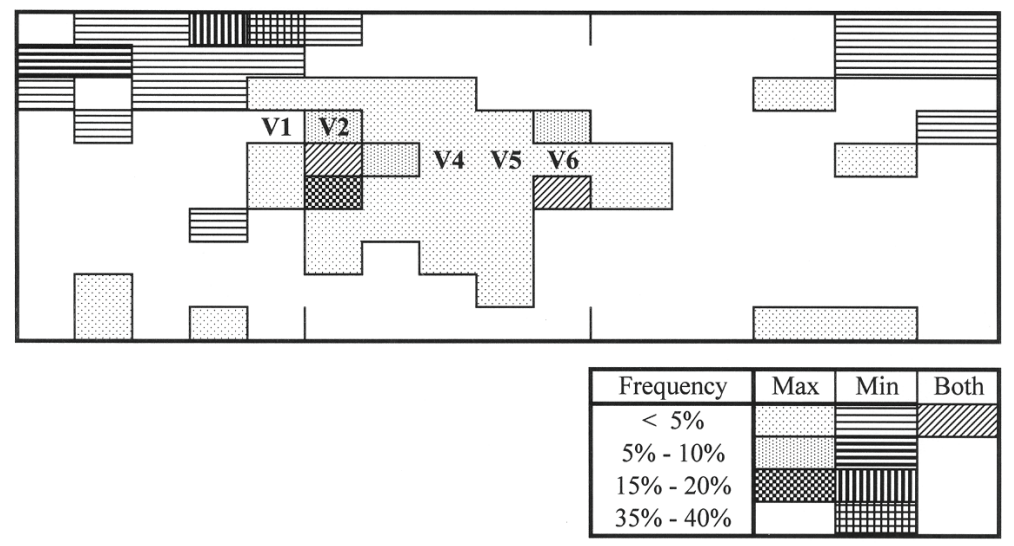

Fig. 3. Positions of $P$ wave maxima and minima in single-beat maps of all analyzed groups. The short vertical lines in the map depict the position of sternum and the left mid-axillary line. Approximate positions of standard chest leads are also marked. Frequency means the appearance of either maximum or minimum (or both) compared to all 166 maps.

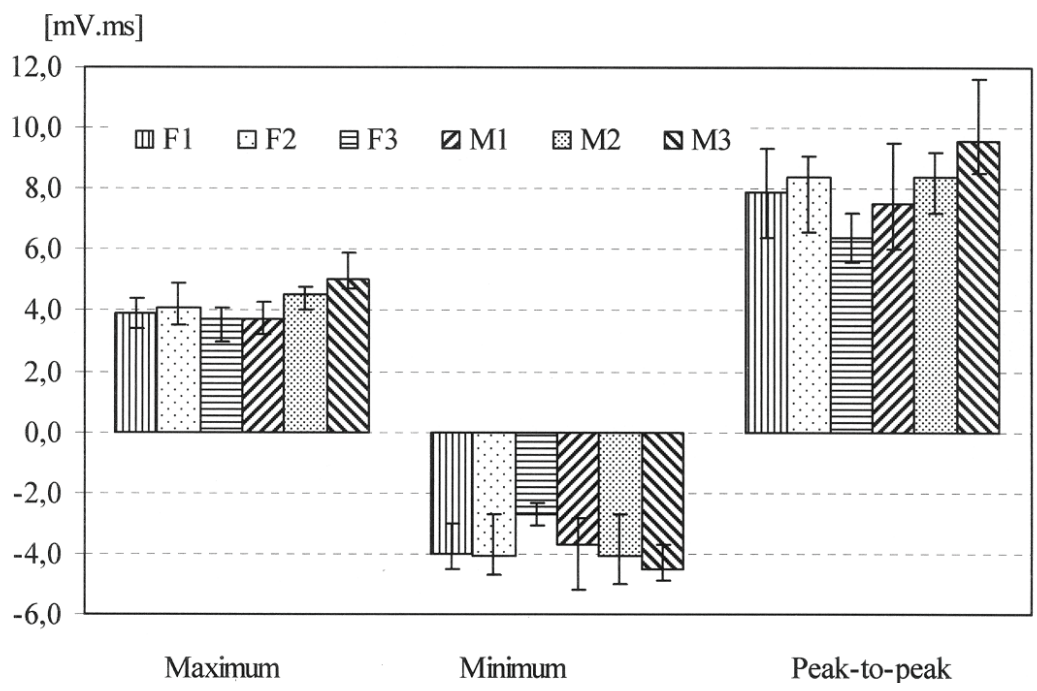

Fig. 4. Medians with $95 \%$ confidence intervals of isointegral $P$ wave extreme values of all analyzed groups.

The highest values of extrema in the M3 group could be at least partially explained by the significantly longer $\mathrm{P}$ waves in this group ( $87 \pm 9 \mathrm{~ms})$ against groups F3 (80 $\pm 12 \mathrm{~ms}, p<0.005)$, M1 (74 $\pm 8 \mathrm{~ms}, p<0.001)$, and $\mathrm{M} 2(81 \pm 11 \mathrm{~ms}, p<0.05)$.

The lowest values of extrema in the F3 group remain unclear as there was no correlation either with $\mathrm{P}$ wave duration or with chest geometry or body shape. There was no significant difference in chest circumferences between groups F3 and F2 $(87 \pm 5 \mathrm{~cm}$ versus $83 \pm 10 \mathrm{~cm}$ ). There was no significant difference in body mass index between group F3 and groups F2 $\left(21.4 \pm 2.3 \mathrm{~kg} \cdot \mathrm{m}^{-2}\right.$ versus $\left.20.3 \pm 3.3 \mathrm{~kg} \cdot \mathrm{m}^{-2}\right)$ and $\mathrm{M} 3$ $\left(22.0 \pm 1.9 \mathrm{~kg} \cdot \mathrm{m}^{-2}\right)$.

The two marked locations of maxima in single beat maps as well as in mean maps could be explained by dominant electrical activity of either the right atrium (maximum to the left of the lower part of sternum) or the left atrium (maximum in the area of the left axilla). Whether this is due to increased dimension or changed position of the atria or any other reason, remains unclear and needs further, specially designed, studies.

Ignoring the heart and chest geometry, the obtained 3 types of isointegral $P$ wave maps (Fig. 1) were visually compared with those obtained during atrial pacing by SippensGroenewegen et al. (1998). Type A resembled the maps paced from the right atrium close to the septum, type B resembled the maps paced from the right atrium close to the superior vena cava and the right atrial appendage, and type $\mathrm{C}$ resembled the map paced from the right atrium close to the crista terminalis and the trabeculated right atrium. Solving the problem whether the three found types of atrial activation are connected with different positions of the pacemaker or are a consequence of geometrical differences, needs future, specially designed studies. 
Nevertheless, the usefulness of the limited lead system to record $\mathrm{P}$ wave maps comparable with those obtained with full lead systems was shown and new data were presented.

\section{Acknowledgements}

This study was in part supported by grants VEGA 1/4271/07 and KEGA 3/4088/06 offered by the Ministry of Education, Slovak Republic.

\section{References}

BARR RC, SPACH MS, HERMAN-GIDDENS GS: Selection of the number and positions of measuring locations for electrocardiography. IEEE Trans. Biomed Eng 18: 125-138, 1971.

IKEDA K, KUBOTA I, YASUI S: Effects of lung volume on body surface electrocardiogram. Isointegral analysis of body surface maps in patients with chronic pulmonary emphysema. Jpn Circ J 49: 284-291, 1985.

ISHIHARA H, TUCHIYA S, HOSAKI J, KAWANO S, SAWANOBORI T, HIRAOKA M: The isopotential body surface atrial maps in healthy children of different age groups. Jpn Circ J 51: 520-526, 1987.

KALKA D, JAGIELSKI J, BANASIAK W, SOBIESZCZANSKA MA, TELICHOWSKI A, FUGLEWICZ A, PIEROG M, PONIKOWSKI P, JAGIELSKI D, KALKA-GEBALA R, GAJKOWSKI E: Use of body surface heart potential mapping for registration of electrical phenomena in the atrium (in Polish). Pol Arch Med Wewn 96: 234-241, 1996.

KAWANO S, SAWANOBORI T., HIRAOKA M: Human body surface mapping during atrial depolarization in normal and diseased subjects. J Electrocardiol 16: 151-159, 1983.

KOZLÍKOVÁ K: Body surface integral maps, their characteristics and methods of quantitative analysis (in Slovak). Bratisl Lek listy 91: 815-823, 1990.

KOZLÍKOVÁ K, MARTINKA J: Age and sex variability of initial parts of the QRS complex displayed in isointegral maps of young people. Acta Medica (Hradec Králové) 47: 317-321, 2004.

MIRVIS DM: Body surface distribution of electrical potential during atrial depolarization and repolarization. Circulation 62: 167-173, 1980.

POPPEROVÁ E, SABOLOVÁ K, MACO M, KOZLÍKOVÁ K, PETRÁŠOVÁ H, WOLFOVÁ A, NOVOTNÁ T: Two types of atrial activation in adolescents (in Slovak). Bratisl Lek Listy 89: 766-769, 1988.

ROSÍK V, TYŠLER M, TURZOVÁ M: Portable device of for ECG mapping. In: Proceedings of International Conference of Measurement, FROLLO I, PLAČKOVÁ A (eds), SAV, Bratislava, 1997, pp 367-370.

SIPPENSGROENEWEGEN A, PEETERS HA, JESSURUM ER, LINNEBANK AC, DE MEDINA EOR, LESH MD, VAN HEMEL NM: Body surface mapping during pacing at multiple sites in the human atrium. P-wave morphology of ectopic atrial activation. Circulation 97: 369-380, 1998.

SIPPENSGROENEWEGEN A, LESH MD, ROITHINGER FX, ELLIS WS, STEINER PR, SAXON LA, LEE RJ, SCHEINMAN MM: Body surface mapping of counterclockwise and clockwise typical atrial flutter: A comparative analysis with endocardial activation sequence mapping. J Am Coll Cardiol 35: 1276-1287, 2000.

SIPPENSGROENEWEGEN A, NATALE A, MARROUCHE NF, BASH D, CHENG J: Potential role of body surface ECG mapping for localization of atrial fibrillation trigger sites. $J$ Electrocardiol 37 (Suppl): 47-52, 2004.

SLEIMAN O, MURÍN J, KOZLÍKOVÁ K: Is atrial fibrillation an adaptive mechanism of heart failure? Exp Clin Cardiol 5: 1-4, 2000.

Statgraphics ${ }^{\circledR}$ PLUS, version 3 for Windows. User manual. Rockville: Manugistics, Inc., 1997, 738 pp.

SZLEJF C, RAYS J, GEBARA OCE, VIEIRA NW, PIERRI H, NUSSBACHER A, SERRO-AZZUL JB, SAMESINA N, PASTORE CA, WAJNGARTEN M: Relation between the behaviors of P-wave and QT dispersions in elderly patients with heart failure. Arq Bras Cardiol 79: 497-499, 2002.

TACCARDI B: Body surface distribution of equipotential lines during atrial depolarization and ventricular repolarization. Circul Res 19: 865-878, 1966.

\section{Corresponding author}

Katarina Kozlíková, Institute of Medical Physics and Biophysics, Faculty of Medicine Comenius University, Sasinkova 2,81372 Bratislava, Slovakia. E-mail: katarina.kozlikova@fmed.uniba.sk. 